\title{
Analisa Gangguan Dan Upaya Perbaikan Motor Filter Sirkulasi Udara Pada Motor Kiln Main Drive (461kl1m\#2) di PT.Indocement Plant 12 Tarjun
}

\author{
A.Agung Irhandy Pradana S. ${ }^{1}$ \\ Prodi Teknik elektro,Universitas Islam Kalimantan ${ }^{1}$ \\ Email : andiagung562@gmail.com,
}

\begin{abstract}
Abstrak - Seringnya terjadi stop produksi dalam 5 bulan terakhir yang diakibatkan oleh tingginya temperatur motor kiln menyebabkan proses produksi clingker tidak maksimal. Dalam hal ini penulis dan electrical department akan menganalisa penyebab gangguan dan akan melakukan perbaikan untuk memaksimalkan produksi clingker. Penelitian ini menggunakan jenis rancangan eksperiment dan mengumpulkan data dengan cara observasi. Penyebab temperatur motor tinggi di karenakan tidak maksimalnya kinerja pendingin motor. Uji hipotesa analisis data koefisien korelasi pearson di gunakan untuk menentukan penyebab permasalahan pendingin motor, dari hasil pengujian analisa korelasi maka di buatlah lubang saluran udara masuk dan keluar supaya sirkulasi pendingin motor tidak di tempat, dan memberikan filter tambahan untuk menjaga kualiatas udara yang masuk, modifikasi ini berhasil menurunkan bahkan menghilangkan gangguan temperatur tinggi pada motor kiln.
\end{abstract}

Kata kunci : Rotary kiln, Motor DC, Clingker

\section{PENDAHULUAN}

Rotary Kiln merupakan suatu alat yang mengolah clingker sebagai campuran material pembuatan semen, material dipanaskan sampai suhu $1350-1400^{\circ} \mathrm{C}$. Untuk menggerakkan
Rotary Kiln tersebut terdapat 2 buah motor main drive 24-810Vdc berkapasitas masingmasing $725 \mathrm{KW}$. Motor kiln Main drive (461kl1m\#2) mengalami gangguan sebanyak 16 kali dalam waktu 5 bulan, sebanyak 6 kali gangguan temperatur tinggi menjadi penyebab utama. dan tercatat motor kiln stop beroprasi sebanyak 6 kali karena tingginya temperatur pada motor. Motor kiln akan langsung trip jika temperature bearing mencapai $85^{\circ} \mathrm{C}$ atau temperatur winding mencapai $95^{\circ} \mathrm{C}$. Demi Kelancaran Proses produksi dan menekan angka kerugian perlu di lakukan analisa penyebab temperatur naik pada motor kiln (461kl1m\#2). Maka dari itu penulis dan team berusaha maksimal mencari ide terbaik untuk mengatasi tinggiya temperatur pada motor kiln, berdasarkan latar belakang permasalahan ini maka penulis menentukan rumusan masalah yaitu bagaimana cara menentukan penyebab dominan gangguan pada motor kiln main drive dengan analisis danta koefisien korelasi pearson.

\section{TINJAUAN PUSTAKA}

Motor Arus Searah ialah suatu mesin yang berfungsi untuk mengubah Energi Listrik Arus Searah (Listrik DC) menjadi Energi Gerak atau Energi Mekanik, dimana Energi Mekanik tersebut berupa putaran dari Rotor.Prinsip kerja motor dc didasarkan pada prinsip bahwa jika sebuah konduktor yang dialiri arus listrik diletakkan dalam medan magnit, maka 
tercipta gaya pada konduktor tersebut yang cenderung membuat konduktor berotasi.

Kiln mencakup dinding berbentuk silinder yang mempunyai ujung masukan dan ujung luaran. Kiln diletakkan miring agar ujung luaran berada di posisi yang lebih rendah dari pada ujung masukan agar dapat memproses material yang dimasukkan. Material mengalir dari ujung masukan menuju ke ujung luaran.

Metode Statistik yang digunakan dalam analisa data adalah koefisien korelasi Pearson. Koefisien korelasi digunakan untuk mengetahui kuat atau tidaknya hubungan antara variabel-variabel bebas dan variabel tidak bebas. Nilai koefisien korelasi berada antara 1 dan $-1(-1 \leq \mathrm{r} \leq 1)$. Variabel-variabel dikatakan memiliki korelasi yang kuat jika nilai koefisien korelasinya lebih besar dari 0,5 atau lebih kecil dari -0,5. Jika nilai koefisien korelasinya positif berarti kenaikan (penurunan) nilai variabel bebas pada umumnya diikuti oleh kenaikan (penurunan) nilai variabel tidak bebas, sedangkan jika nilai koefisien korelasinya negatif berarti kenaikan (Penurunan) nilai variabel bebas pada umumnya diikuti oleh penurunan (Kenaikan) nilai variabel tidak bebas. Adapun rumus perhitungan untuk menentukan koefisien korelasi $r$ antara variabel tidak bebas $Y$ terhadap variabel bebas $X$ ditunjukkan pada per samaan 2-1 dengan $n$ jumlah data (Gaspersz, 1992).

\section{HASIL PENELITIAN}

\section{Analisa Penyebab Temperatur}

\section{Tinggi pada Motor Kiln}

Berdasarkan temuan di lapangan, filter udara pendingin motor buntu karena debu dari carbon brush menempel pada filter udara, dan tidak adanya lubang pembuangan udara panas dari dalam motor, ini memperburuk kualiatas kerja pendingin dengan system udara yang hanya bersirkulasi di dalam ruangan motor saja.
Tabel 1. Penyebab di Duga Dominan

\begin{tabular}{|c|c|l|c|l|}
\hline Faktor & \multicolumn{3}{|c|}{} \\
\hline & 1 & $\begin{array}{l}\text { Motor } \\
\text { Panas }\end{array}$ & 5 & Bearing \\
\cline { 2 - 5 } Mesin & 2 & $\begin{array}{l}\text { Connection } \\
\text { Kabel }\end{array}$ & 6 & $\begin{array}{l}\text { Tacho } \\
\text { Generator }\end{array}$ \\
\cline { 2 - 5 } & 3 & $\begin{array}{l}\text { Cooling } \\
\text { Fan }\end{array}$ & 7 & $\begin{array}{l}\text { Lubang } \\
\text { Pembuangan } \\
\text { Udara Tidak } \\
\text { Ada }\end{array}$ \\
\cline { 2 - 5 } & 4 & $\begin{array}{l}\text { Debu } \\
\text { Carbon } \\
\text { Brush } \\
\text { Menempel } \\
\text { di Filter }\end{array}$ & 8 & Filter Udara \\
\hline
\end{tabular}

\section{Menentukan Penyebab}

\section{Uji Hipotesa 1}

Penyebab Temperatur Ruangan Motor

Panas

Tujuan pengujian : Mengetahui Hubungan antara Frekuensi Sirkulasi Udara Tertutup dengan Lamanya Tidak Ada Lubang Pembuangan

Indikator $\mathrm{n}$ : Banyaknya Pasangan Data $\mathrm{x}$ dan y

Indikator $\mathrm{x}$ :Filter Udara Tertutup (Kali)

Indikator y : Tidak Ada Lubang

Pembuangan (Jam)

Waktu Pengujian: 16 - 24 Desember 2019

Metode: Pengamatan

Objek Pengamatan : Motor Kiln Main

Drive (461KL1M\#2)

Tabel 2. Penyebab Temperatur Ruangan Motor Panas

\begin{tabular}{|c|c|c|c|c|c|c|}
\hline Tanggal & $\mathrm{n}$ & $\mathrm{x}$ & $\mathrm{y}$ & $\mathrm{x}^{2}$ & $\mathrm{y}^{2}$ & $\mathrm{xy}$ \\
\hline 16/12/2019 & 1 & 4 & 5 & 16 & 25 & 20 \\
\hline 17/12/2019 & 2 & 7 & 8 & 49 & 64 & 56 \\
\hline 18/12/2019 & 3 & 6 & 6 & 36 & 36 & 36 \\
\hline 19/12/2019 & 4 & 5 & 5 & 25 & 25 & 25 \\
\hline 20/12/2019 & 5 & 2 & 4 & 4 & 16 & 8 \\
\hline 23/12/2019 & 6 & 2 & 4 & 4 & 16 & 8 \\
\hline 24/12/2019 & 7 & 3 & 3 & 9 & 9 & 9 \\
\hline Total & & $\mathbf{2 9}$ & $\mathbf{3 5}$ & 143 & 191 & 162 \\
\hline
\end{tabular}

Sumber : Pengecekan di Lapangan 16/12/2019-24/12/2019 


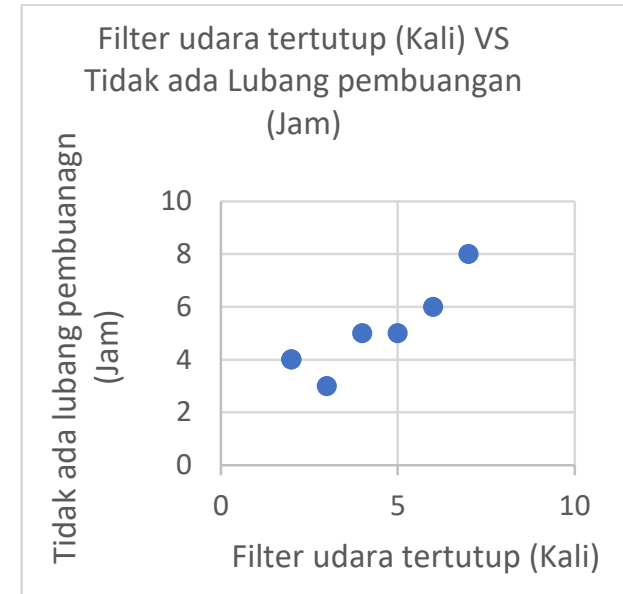

Gambar 3. Penyebab Temperatur Ruangan Motor Panas

Dari Scatter Diagram diatas diketahui bahwa terdapat korelasi positif kuat antara filter sirkulasi udara tertutup dengan tidak ada lubang pembuangan, hal ini dapat dilihat semakin lama tidak ada lubang pembuangan maka filter akan semakin tertutup, ini terlihat dari nilai koefisien korelasi sebesar $r=0,905$ dan $r^{2}=0,819$ dengan kekuatan korelasi sebesar $81,9 \%$, Dengan demikian tidak ada lubang pembuangan merupakan penyebab dominan motor kiln main drive terganggu, untuk itu penyebab tersebut akan di lakukan perbaikan.

\section{Uji Hipotesa 2}

Penyebab Debu Menempel di Dalam Filter Tujuan pengujian : Mengetahui Hubungan antara Frekuensi Filter Cepat Kotor dengan Lamanya Udara Terhambat Indikator $\mathrm{n}$ : Banyaknya Pasangan Data $\mathrm{x}$ dan y

Indikator $\mathrm{x}$ : Filter Cepat Kotor (Kali)

Indikator y : Udara Terhambat (Jam)

Waktu Pengujian: 17/Desember/2019-

03/Januari/2020

Metode: Pengamatan

Objek Pengamatan : Motor Kiln Main

Drive (461KL1M\#2)
Tabel 3. Penyebab Debu Menempel di Dalam Filter

\begin{tabular}{|c|c|c|c|c|c|c|}
\hline Tanggal & $\mathbf{n}$ & $\mathbf{x}$ & $\mathbf{y}$ & $\mathbf{x}^{\mathbf{2}}$ & $\mathbf{y}^{\mathbf{2}}$ & $\mathrm{xy}$ \\
\hline $\mathbf{1 7 / 1 2 / 2 0 1 9}$ & 1 & 10 & 9 & 100 & 81 & 90 \\
\hline $\mathbf{1 9 / 1 2 / 2 0 1 9}$ & 2 & 7 & 8 & 49 & 64 & 56 \\
\hline $\mathbf{2 3 / 1 2 / 2 0 1 9}$ & 3 & 7 & 8 & 49 & 64 & 56 \\
\hline $\mathbf{2 6 / 1 2 / 2 0 1 9}$ & 4 & 9 & 8 & 81 & 64 & 72 \\
\hline $\mathbf{2 7 / 1 2 / 2 0 1 9}$ & 5 & 5 & 7 & 25 & 49 & 35 \\
\hline $\mathbf{0 2 / 0 1 / 2 0 2 0}$ & 6 & 6 & 6 & 36 & 36 & 36 \\
\hline $\mathbf{0 3 / 0 1 / 2 0 2 0}$ & 7 & 9 & 9 & 81 & 81 & 81 \\
\hline Total & & $\mathbf{5 3}$ & $\mathbf{5 5}$ & $\mathbf{4 2 1}$ & $\mathbf{4 3 9}$ & $\mathbf{4 2 6}$ \\
\hline
\end{tabular}

Sumber : Pengecekan di Lapangan 17/12/2019-03/01/2020

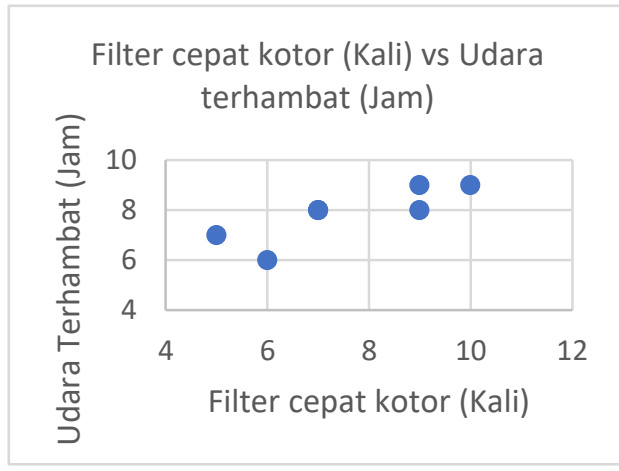

Gambar 4. Penyebab Debu Menempel di Dalam Filter

Dari scatter diagram diatas diketahui bahwa terdapat korelasi positif kuat antara filter cepat kotor dengan lamanya udara terhambat, hal ini dapat dilihat pada kondisi dimana semakin lama udara terhambat maka filter cepat kotor, terlihat dari nilai koefisien korelasi sebesar $r$ $=0,823$ dan $\mathrm{r}^{2}=0,677$ dengan kekuatan korelasi sebesar $67,7 \%$, dengan demikian penyebab debu menempel didalam filter merupakan penyebab dominan, untuk itu penyebab tersebut akan di lakukan perbaikan.

\section{Penetapan Penyebab Dominan}

Hasil Uji Hipotesa yang sudah dilakukan, diketahui bahwa 2(dua) penyebab memiliki korelasi yang kuat dan dinyatakan sebagai penyebab dominan atas frekuensi gangguan pada motor kiln main drive. Hal ini sebagaimana terlihat dalam tabel4. 
Tabel 4. Penyebab Dominan

\begin{tabular}{|c|c|c|c|c|}
\hline No. & Penyebab Dominan & $\mathrm{r}$ & $\mathrm{r}^{2}$ & $\%$ \\
\hline 1 & $\begin{array}{c}\text { Tidak Ada Lubang Pembuangan } \\
\text { Udara Panas dan Debu }\end{array}$ & 0,905 & 0,819 & 81,9 \\
\hline 2 & Debu Menempel di Dalam Filter & 0,823 & 0,677 & 67,7 \\
\hline
\end{tabular}

Sumber : Hasil Uji Hipotesa Perhitungan

Korelasi dengan Rumus Pearson

\section{KESIMPULAN}

Kesimpulan yang diambil dari penelitian ini adalah penyebab temperatur motor tinggi di karenakan buntunya sirkulasi udara karena debu dari carbon brush yang menepel di filter, dan juga tidak adanya fasilitas pembuangan udara panas dan debu dari dalam motor, selain itu sirkulasi pendingin yang hanya berada di dalam motor saja, dan untuk mengetahui penyebab dominan yaitu dengan cara uji hipotesa analisis korelasi dengan rumus pearson, selanjutnya di lakukanlah modifikasi sesuai hasil uji hipotesa.

\section{DAFTAR PUSTAKA}

Ali, M. (2012). Kontrol Kecepatan Motor DC Menggunakan PID Kontroler yang Ditunning dengan Firefly Algorythm. Jurnal Intake, 3, 2. Dipetik September 05, 2020

Ananda, S. A., \& Soewangsa, E. T. (2003, Maret). Studi Karakteristik Motor DC Penguat Luar Terhadap Posisi Sikat. Jurnal Teknik Elektro, 1, 51-56. Dipetik September 05, 2020

Ammarullah, M., Prakoso, A., Wicaksono, D., Fadhlurrahman, I., Yani, I., \& Basri, H. (2018, Juli 02). Analisis Perpindahan Kalor Konveksi pada Rotary Kiln di PT. Semen Baturaja (Persero) Tbk. Jurnal Rekasyasa Mesin, 18, 2. Dipetik September 05, 2020.
Budiwati, T., Budiyono, A., Setyawati, W., \& Indrawaty, A. (2010). Analisis Korelasi Pearson Untuk Unsur-unsur Kimia Air Hujan di Bandung. Jurnal Sains Dirgantara, 7, 2. Dipetik September 06, 2020. 